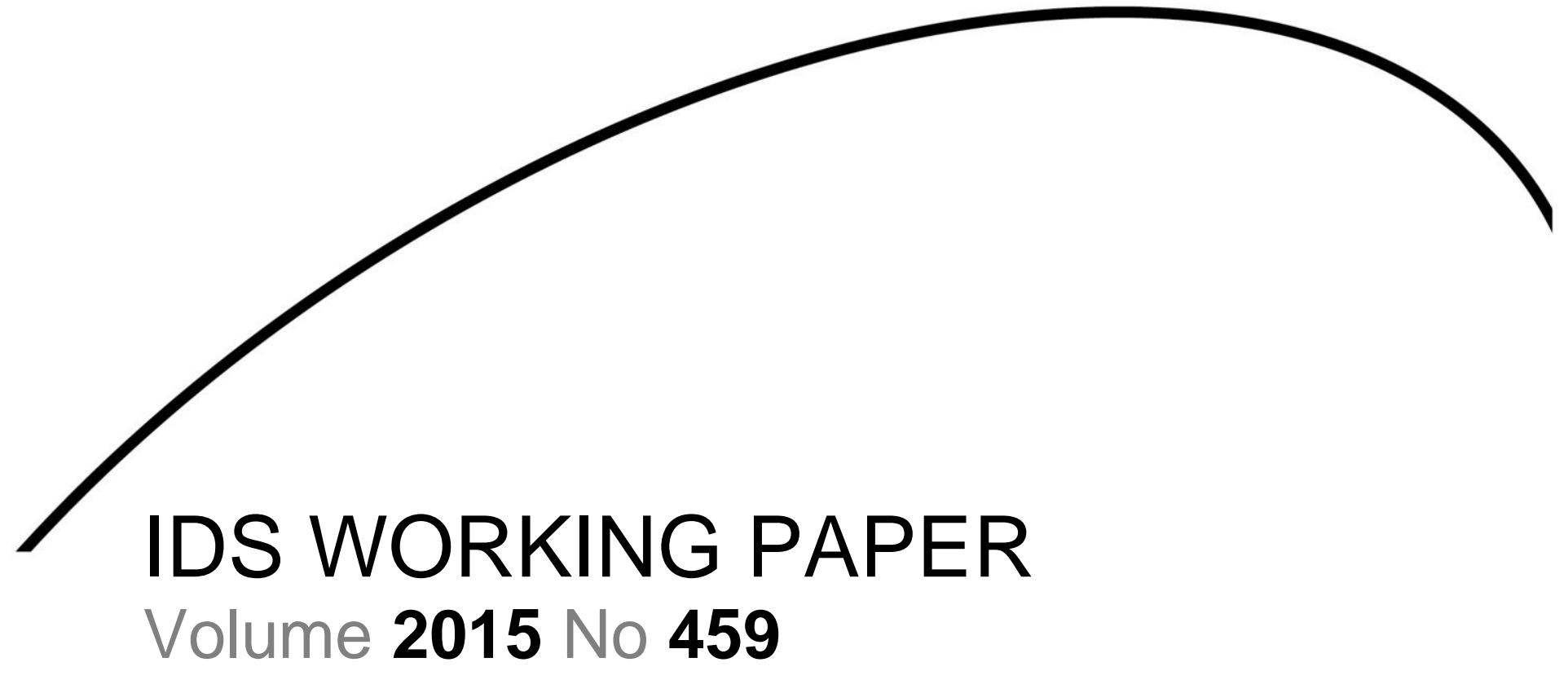

Design, Monitoring and Evaluation of Resilience Interventions: Conceptual and Empirical Considerations

Christophe Béné, Tim Frankenberger and Suzanne Nelson July 2015 


\section{Disclaimer}

Support for this paper was provided by Technical and Operational Performance Support (TOPS), a U.S. Agency for International Development (USAID) programme. The authors' views expressed in this publication do not necessarily reflect the views of the TOPS programme, USAID or of the United States Government.

www.thetopsprogram.org/about-tops

Design, Monitoring and Evaluation of Resilience Interventions: Conceptual and Empirical Considerations

Christophe Béné, Tim Frankenberger and Suzanne Nelson

First published by the Institute of Development Studies in July 2015

IDS Working Paper 459

(C) Institute of Development Studies 2015

ISSN: 2040-0209 ISBN: 978-1-78118-248-2

A catalogue record for this publication is available from the British Library.

All rights reserved. Reproduction, copy, transmission, or translation of any part of this publication may be made only under the following conditions:

- with the prior permission of the publisher; or

- with a licence from the Copyright Licensing Agency Ltd., 90 Tottenham Court Road, London, W1P 9HE, UK,

or from another national licensing agency; or

- under the terms set out below.

This publication is copyright, but may be reproduced by any method without fee for teaching or nonprofit purposes, but not for resale. Formal permission is required for all such uses, but normally will be granted immediately. For copying in any other circumstances, or for re-use in other publications, or for translation or adaptation, prior written permission must be obtained from the publisher and a fee may be payable.

\section{Available from:}

Communications and Engagement Unit, Institute of Development Studies, Brighton BN1 9RE, UK

Tel: +44 (0) 1273915637

E-mail: bookshop@ids.ac.uk

Web: www.ids.ac.uk/publications

IDS is a charitable company limited by guarantee and registered in England (No. 877338) 


\title{
Design, Monitoring and Evaluation of Resilience Interventions: Conceptual and Empirical Considerations
}

Christophe Béné, Tim Frankenberger and Suzanne Nelson

\begin{abstract}
Summary
As resilience programming gains more and more prominence as an approach for addressing chronic vulnerability of populations exposed to recurrent shocks and stressors, empirical evidence will be needed for measuring how well households, communities, and systems manage shocks and stressors and how interventions and programmes that are designed to strengthen these capacities, perform. However, despite progress on the conceptual side, academics, practitioners and donors are still struggling with pragmatic issues - in particular, how to measure, and monitor and evaluate resilience interventions. Developing a robust resilience measurement and Monitoring and Evaluation (M\&E) framework is therefore a priority. The objective of this paper is to contribute to this agenda. After reviewing some of the progress made recently in relation to resilience measurement, the paper adopts a logical framework (logFram) and uses both theoretical and empirical examples to present the different components that an project M\&E needs to include in order to monitor adequately resilience.
\end{abstract}

Keywords: resilience; monitoring and evaluation; measurement; impact; assessment.

Christophe Béné worked with the Vulnerability and Poverty Reduction team at IDS for five years (2010-2014) before joining the International Center for Tropical Agriculture (CIAT) based in Cali, Colombia. There he works as Senior Policy Advisor in the Decision and Policy Analysis Program (DAPA). He has over 15 years of experience in inter-disciplinary research and advisory work focusing on poverty alleviation, vulnerability and food security, initially through the analysis of the socio-political economy of natural resources, more recently through resilience analysis and evaluation of vulnerability reduction programmes in relation to disasters and climate change.

Tim Frankenberger is the President of TANGO International and a global expert on food security, livelihood approaches and resilience. Tim has over 30 years of experience in international development, with specialised skills in project design, M\&E, and policy analysis. He previously served as Senior Food Security Advisor and Livelihood Security Coordinator at CARE and a farming systems research specialist at the University of Arizona. Tim has published numerous articles on household food security and resilience. Tim's graduate work includes an MA as well as doctoral studies in Anthropology with a minor in Agricultural Economics.

Suzanne Nelson is a Senior Research Scientist with TANGO International. Trained in agronomy and plant sciences, she has many years of experience in developing countries working in conservation and use of agro-biodiversity, natural resources management, and community-level capacity building. Her current research focuses on resilience, adaptation to climate change, food and livelihood security, vulnerability and poverty alleviation. 


\section{Contents}

Summary, keywords and author notes 3

Acknowledgements $\quad 5$

Acronyms $\quad 5$

Introduction $\quad 6$

$1 \quad$ What do we know about measuring resilience? $\quad 7$

$\begin{array}{lll}1.1 & \text { Resilience as a mean rather than an end } & 7\end{array}$

1.2 Resilience measurement integrated framework 8

1.3 Emphasis on shocks and stressors 9

1.4 Resilience as a combination of capacities 9

1.5 Certain responses can lead to undesirable outcomes 10

1.6 Combined effects of shocks/stressors and the responses employed to

$\begin{array}{lll}1.7 & \text { More than just vulnerability analysis } & 12\end{array}$

1.8 Resilience capacity is measured at multiple levels and scales 13

1.9 Building resilience capacities 13

$2 \quad$ Monitoring and evaluation of resilience interventions 14

$\begin{array}{ll}2.1 & \text { Intermediate outcome indicators } \\ & 16\end{array}$

$\begin{array}{ll}2.2 & \text { Outcome indicators } \\ & 17\end{array}$

$\begin{array}{lll}2.3 & \text { Impact indicators } & 18\end{array}$

$\begin{array}{lll}2.4 & \text { Shocks and stressors indicators } & 19\end{array}$

$\begin{array}{ll}2.5 & \text { Data collection } \\ 2.6 & 19\end{array}$

$\begin{array}{ll}2.6 \text { Monitoring contextual changes } & 20\end{array}$

3 Conclusion $\quad 20$

Annex 1 Resilience conceptual framework 22

Glossary $\quad 23$

References $\quad 24$

Figures

Figure 1 Generic theory of change of a resilience intervention $\quad 7$

Figure 2 Resilience measurement integrated framework 8

Figure 3 Resilience as the result of absorptive, adaptive, and

Figure 4 Conceptual representation of a resilience framework 12

$\begin{array}{ll}\text { Figure } 5 & \text { Resilience capacity-mediated relationship between shock exposure } \\ & \text { and household food insecurity (HFIAS) }\end{array}$

Figure 6 Logframe for M\&E of resilience programming interventions 16

Tables

Table 1 Coping Strategy Index (CSI) 


\section{Acknowledgements}

The authors would like to thank Greg Collins (USAID), Mark Constas (Cornell University), and Richard Longhurst (Institute of Development Studies) for their comments on earlier drafts of this paper. We also thank Mark Fritzler and the Technical and Operational Performance Support (TOPS) program for support. The paper was also informed by research implemented under the project 'Tangled in their own (safety)-nets? Resilience, adaptability, and transformability of small-scale fishing communities in the face of the World fisheries crisis' funded by the UK DFID-ESRC joint scheme programme on Poverty Alleviation.

\section{Acronyms}

BRACED

CCA

CES-D

CIAT

CSI

DAPA

DFID

DRR

DRM

FEWSNET

FSIN

HDDS

HFIAS

HHS

IPC

M\&E

NGO

NSP

PRIME

PTSD

SIDA

TOPS

USAID
Building Resilience and Adaptation to Climate Extremes and Disasters Climate Change Adaptation

Center for Epidemiologic Studies Depression Scale

International Center for Tropical Agriculture

Coping Strategies Index

Decision and Policy Analysis Program

UK Department for International Development

Disaster Risk Reduction

Disaster Risk Management

Famine Early Warning Systems Network

Food Security Information Network

Household Dietary Diversity Score

Household Food Insecurity Access Score

Household Hunger Scale

Initial Planning Conference

Monitoring and Evaluation

Non-governmental Organisation

Nutrition Surveillance Programme

Pastoralist Areas Resilience Improvement and Market Expansion

Post-traumatic Stress Disorder

Swedish International Development Cooperation

Technical and Operational Performance Support

U.S. Agency for International Development 


\section{Introduction}

Over the last three years, the commitment by various donors and development agencies to support resilience-building initiatives in relation to their humanitarian and/or development agenda has been substantial. Although a precise global figure is difficult to estimate, some unofficial calculations suggest figures exceeding US\$4-5 billion. The EU alone has announced that it intends to mobilise $€ 1.5$ billion for resilience programming in the Sahel between 2014 and 2020 through the $11^{\text {th }}$ European Development Fund. The UK Department for International Development (DFID) recently committed $£ 140$ million through their Building Resilience and Adaptation to Climate Extremes and Disasters (BRACED) programme funded under the UK's International Climate Fund. USAID, the Rockefeller Foundation, and Swedish International Development Cooperation (SIDA) have jointly committed US\$100 million through the Global Resilience Partnership. In addition to these bilateral and multilateral commitments, countries themselves are investing increasing amounts of their national budgets in resilience programmes. The government of Kenya for instance has committed US $\$ 1.6$ billion (in addition to US $\$ 1.5$ billion in donor commitments) through its National Drought Management Authority. Non-governmental organisations (NGOs) are also getting involved. More than 15 major international NGOs (including Action Aid, Christian Aid, Care International, Concern Worldwide, Mercy Corps, Oxfam GB, Plan International, Practical Action, Save the Children, Tearfund, and World Vision) have made resilience one of their major programmatic priorities for the near future and have invested large amounts of human and financial resources in interventions aimed at strengthening resilience.

Major progress has been made recently on understanding resilience in a development context, and some consensus seems to be emerging at the international level regarding an appropriate conceptual definition of resilience. The Resilience Measurement Technical Working Group', for example, defines resilience as 'the capacity that ensures stressors and shocks do not have long-lasting adverse development consequences' (Constas,

Frankenberger and Hoddinott 2014a: 6). In other words, resilience is about the ability of individuals, households, communities, institutions or higher-level systems to adequately deal with shocks and stressors.

Despite progress on the conceptual side, academics, practitioners and donors are still struggling with pragmatic issues - in particular, how to measure, and monitor and evaluate resilience interventions (Vaitla et al. 2012; Béné 2013). Published highlights of the recent international conference on resilience noted for instance: 'questions of what to measure, whom to measure, how often to measure, what methods to use, and at what scale are still being debated' (IFPRI 2014: 7). Yet the issue is important. Without being able to measure resilience, policy-makers, donors, implementing partners and other stakeholders, will not be in a position to identify and support interventions that have the most positive effect on people's ability to respond to and accommodate adverse events. Developing an operational resilience measurement and M\&E framework is therefore a priority. The objective of this paper is to contribute to this agenda. The paper is aimed mainly at practitioners, scholars or development agencies engaged in resilience-building interventions. 


\section{What do we know about measuring resilience?}

This section summarises some of the recent progress that has been made in relation to resilience measurement in the last three years, and highlights the implications of this improved understanding for resilience programming.

\subsection{Resilience as a means rather than an end}

Resilience should not be seen as the final goal of a development programme. Instead resilience should be seen as an intermediate outcome required for achievement of a more fundamental goal related to a longer-term developmental ambition (Béné et al. 2014; Brown 2013; UNDP 2014), typically a measure of wellbeing (e.g., food security, health/nutrition status, poverty) (Constas et al. 2014a). Understanding resilience as a means rather than an end is increasingly acknowledged in the literature and several development agencies have already structured their resilience frameworks to reflect this approach (see, e.g., DFID 2012). As such, this means that programmes cannot have resilience as a primary objective. Rather, this conception emphasises the importance of wellbeing as the ultimate goal of programming.

Framed into a theory of change, this new understanding of resilience implies that programme interventions that focus on resilience strengthening should be designed and implemented so that they lead to an intermediate outcome (e.g., strengthened resilience capacity of the target population), which itself should then lead to an appropriate response outcome (e.g., improved resilience of the target population), which should eventually lead to the programme's ultimate goal, that is, improving the wellbeing of the target population. This generic theory of change for resilience interventions is represented in Figure 1.

\section{Figure 1. Generic theory of change of a resilience intervention}

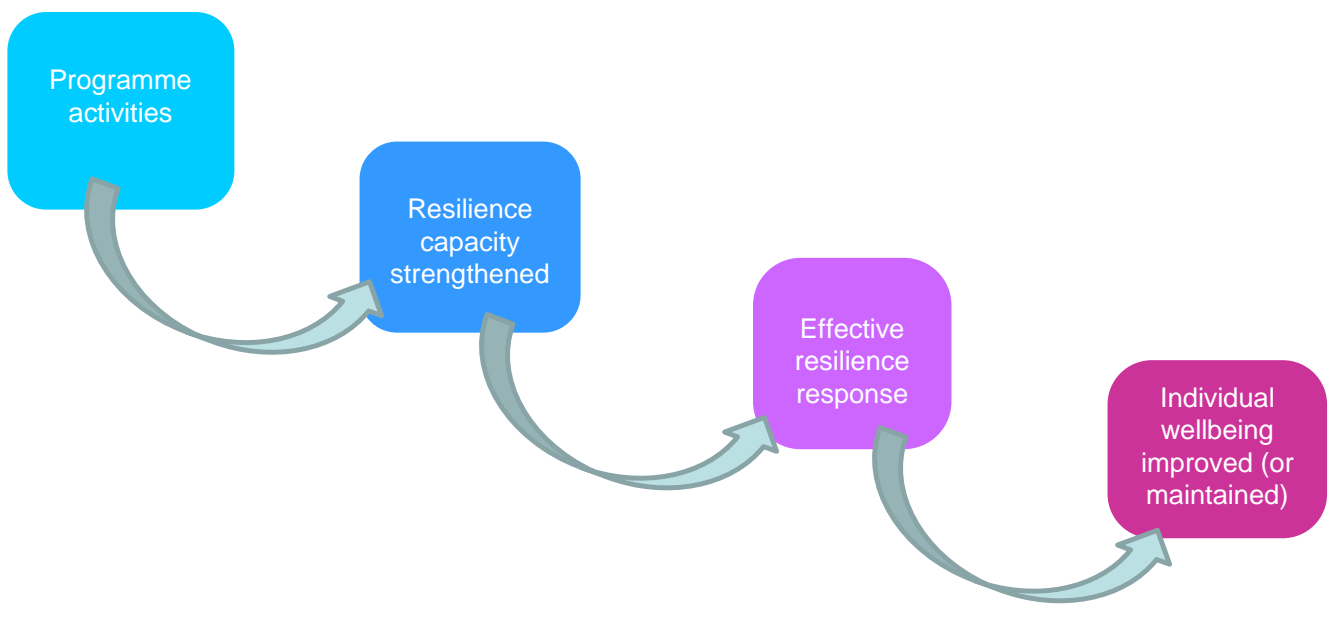

Source: authors' own.

An important element illustrated by Figure 1 is the recognition that the process of formulating a theory of change also brings measurement requirements into focus. In particular, it highlights some of the key components that will need to be included in the M\&E system. These will be discussed in detail in Section 2 below. 


\subsection{Resilience measurement integrated framework}

To measure improvements in resilience, empirical evidence is needed on what factors contribute to it, under what contexts, and for what types of shocks. The ability to measure the relationship between the different components that constitute a resilience analysis (i.e., the relationship between shocks, responses, and future states of wellbeing) depends on the analysis of a number of substantive dimensions and structural features (Constas et al. 2014b). Those highlight the specific indicators and data that need to be collected so that insights related to resilience dynamics can be measured.

In this context, causal frameworks are useful because they focus measurement activities and provide a potential link between the structure of interventions and the organisation of data analysis that follows measurement. The resilience causal framework presented in Figure 2 provides a further organisational scheme in which the task of developing resilience measures can be conceptualised and implemented (Constas et al. 2014b).

\section{Figure 2. Resilience measurement integrated framework}

Resilience Defined as an Instrumental Capacity that Affects Well-Being in the Face of Shocks and Stresses

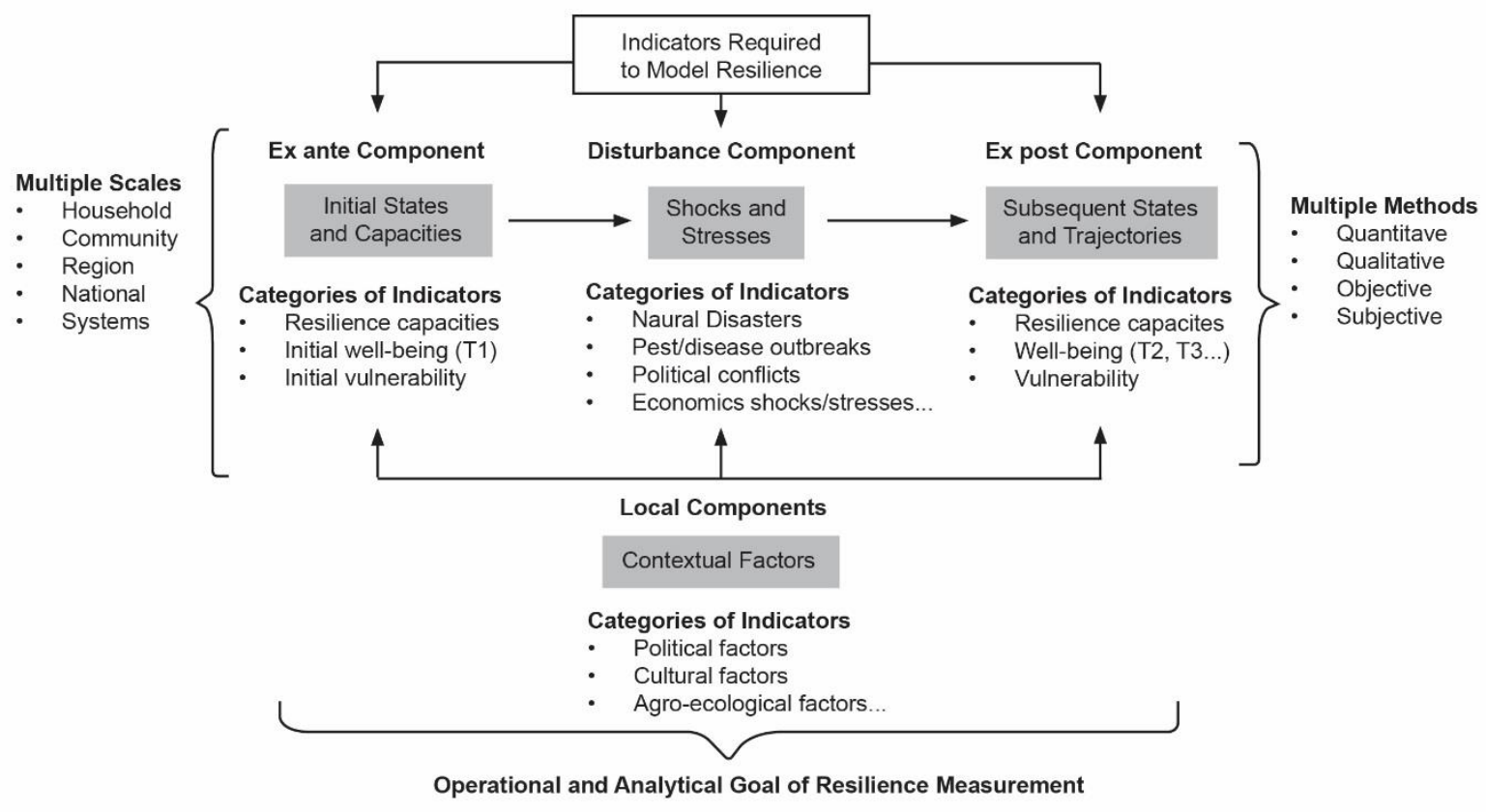

Collect and analyze data to model recovery and well-being trajectories over time as a function of initial states and shocks/stressors, mediated by resilience capacity

Source: Constas et al. (2014b). Reproduced with kind permission of FAO, IFPRI and WFP. ${ }^{2}$

Substantive features comprise initial- and end-state measures, disturbance measures, and capacity measures. The indicators required to measure resilience fall under the following components: i) ex ante component (i.e., initial states and capacities), ii) disturbance component, which represents shocks and stressors, and iii) ex post component that represents subsequent states and trajectories (Constas et al. 2014b). Resilience measurement should be focusing on multiple scales (e.g., individuals, households, community, district/provincial, national and larger systems). 
There are four key factors to consider in measuring resilience:

- Identify the wellbeing outcomes to be achieved, and measure resilience in relation to these outcomes.

- Identify the shocks and stressors that individuals, households, communities and larger systems are exposed to and the severity and duration of these shocks and stressors.

- Measure the absorptive, adaptive and transformative capacities in relation to these shocks and stressors at different levels.

- Identify the responses of individuals, households, communities and larger systems to these shocks and stressors and trajectories of wellbeing outcomes.

The following categories of indicators need to be measured:

- Ex ante component: resilience capacity; initial wellbeing outcomes; and initial vulnerability level.

- Disturbance component: natural disasters; pest/disease outbreaks; political conflicts; and economic shocks/stressors.

- Ex post component: resilience capacity; wellbeing outcomes; and vulnerability level.

All three components must be understood in relation to contextual factors. These contextual factors include a wide range of political, agro-ecological, and cultural conditions that are generally recognised to have a strong influence on households and communities. Agroecological conditions can be considered as both context (from the view point of household or community resilience) as well as part of the resilience system itself (i.e., when higher-level systems are considered).

Structural and methodological features highlight the way in which data will be collected in terms of scale, timing, and types of measurement employed to measure resilience (Frankenberger et al. 2014). Annex 1 illustrates how these dimensions of measurement interact.

\subsection{Emphasis on shocks and stressors}

Resilience interventions are about improving (or at least maintaining) the wellbeing of people in the context of shocks and/or stressors. Thus, analysis of programming designed to strengthen resilience cannot be done without assessing the shocks and stressors (both covariate and idiosyncratic) that affect people's lives. To some extent, a resilience analysis could be seen as a livelihoods analysis, but with a stronger emphasis on the shocks/stressors context ${ }^{3}$ and on the capacities and responses of individuals, households, and communities to deal with these shocks/stressors. In that respect, adopting a resilience lens means recognising the importance of uncertainty, risks, shocks and changes (Berkes, Colding and Folke 2003). It also means recognising that shocks, stressors and trends affect not only individuals and households but also communities, institutions, infrastructures and higher-level systems (e.g., agro-ecological systems, market systems, governance systems). Thus, the unit of analysis and the level of intervention cannot be implemented at the household level only, even if the programme's ultimate goal is to improve or maintain household wellbeing. The M\&E plan must include analysis and measurement of intermediate outcomes (resilience capacity) and outcomes (resilience response) at multiple levels as well.

\subsection{Resilience as a combination of capacities}

Resilience reflects how people or systems (or parts of a system) respond to shocks and stressors. More specifically, it is the ability or the capacity of individuals, groups of people, 
organisations, institutions, or systems to deal effectively with shocks/stressors. It is useful to conceptualise resilience as a property that combines three dimensions (Figure 3): (1) an absorptive capacity that includes all the various risk management strategies by which individuals and/or households moderate or cope with the impacts of shocks on their livelihoods and basic needs; (2) an adaptive capacity that reflects the "capacity to learn, combine experience and knowledge, adjust responses [in a pro-active way] to changing external drivers and internal processes, and continue operating' (Berkes et al. 2003); and (3) a transformative capacity, i.e., the capacity to create an enabling environment through investment in good governance, infrastructure, formal and informal social protection mechanisms, basic service delivery, and policies/regulations that constitute the necessary conditions for systemic change.

Figure 3. Resilience as the result of absorptive, adaptive, and transformative capacities

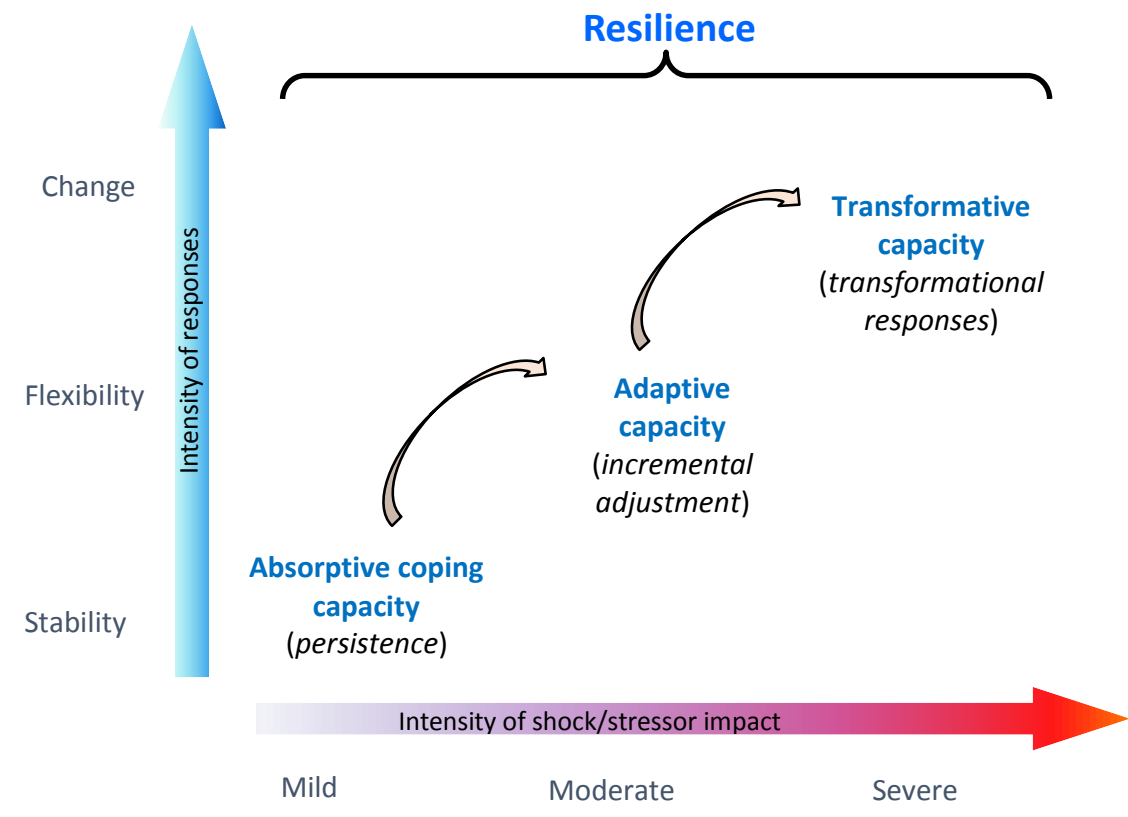

Source: authors' own; Béné et al. (2014).

Note that absorptive, adaptive and transformative capacities can occur simultaneously and are not strictly dependent on the severity of a shock or stressor. For instance, transformative capacity can be built during less stressful times. Furthermore improving enabling environments (e.g., service delivery, governance, infrastructure, policies, access to social protection) can also have a positive synergistic effect on the absorptive and adaptive capacities of households, communities, and higher-level systems.

\subsection{Certain responses can lead to undesirable outcomes}

It is important to realise that not all responses to shocks and stressors necessarily result in positive wellbeing outcomes, either in the short- or longer-term. It is well documented that certain risk management strategies (e.g., distress selling of assets, reduction of expenses or food consumption) can have very detrimental effects on the immediate or long-term wellbeing of households (e.g., nutritional status, food security) (Dercon, Hoddinott and Woldehanna 2005; Hoddinott 2006; Kazianga and Udry 2006; Sinha, Lipton and Yaqub 2002). This detrimental long-term outcome, however, can also be observed in the case of adaptive (or even transformative) responses, leading to what is referred in the climate change literature as "maladaptation" (Barnett and O'Neil 2013; Macintosh 2013). A pertinent example in the context of this discussion would be the case of a household living in the 
coastal belt of Bangladesh (where saline intrusion makes life increasingly difficult), who decides to migrate to Khulna or to Dhaka (provincial and country capitals, respectively). This adaptive/transformative response ${ }^{4}$ could turn out to be positive: the family is taken care of by a wealthy uncle living in Dhaka who manages to provide support for the family to settle and start a new life. But the same decision (to migrate) could lead to negative outcomes: the head of the household fails to find a new job, leading him to engage in some illegal activities while the family, which has no connections and no support, rapidly falls into destitution.

What this particular example tries to convey is that resilience strengthening is not simply about avoiding/preventing negative coping strategies and promoting adaptive or even transformative strategies - as if coping strategies were intrinsically 'bad' and adaptive or transformative responses were naturally 'good'. This polarised view is too simplistic/mechanistic and incorrect (see Béné et al. 2012: 23-25). This Bangladeshi story was chosen precisely to illustrate this point: the strategy adopted by the family is not a coping strategy but an adaptive/transformative response (i.e., they decided to shift livelihood base). Yet, as suggested here, an adaptive response can still lead, in some circumstances, to negative long-term outcomes. In fact the term maladaptation is precisely the recognition of this reality. As documented in the literature (Black et al. 2011), migration can lead to positive changes but can - and does - also lead to negative outcomes.

What this implies is that, fundamentally, resilience interventions are about strengthening the ability of households (or society) to choose - from a whole 'portfolio' of options - what they perceive at that time as the "right" response(s), rather than be forced by circumstance to pick the only option they have at their disposal at that moment, which might be detrimental overall (e.g., selling assets). This is referred to as the 'capacity [to avoid] long-lasting adverse development consequences,' or resilience (Constas et al. 2014a).

\subsection{Combined effects of shocks/stressors and the responses employed to deal with them}

It is also critical to realise that the final wellbeing state (e.g., food security) is not merely the result of an initial shock or stressor (e.g., destruction of assets, loss of livestock), but is rather the combined result of the effect of the shock, the capacities that people drew on, and the response(s) that individuals, households or communities used in an attempt to deal with the shock. That is, when a flood hits a community for example, the observed effect on food security and nutrition - at least in some households - is not the result of the flood event per se, but is rather the result of the effect of the flood event (e.g., destruction of property, loss of crops) and how households used their capacities and responded - or not - to that event. An appropriate response (e.g., using social capital, accessing savings) increases the chance to lead to positive outcomes, while an inappropriate or ill-chosen one often leads to vulnerability. In the present example of a flooded community, some households are likely to be less affected, particularly in the long-term, even if they were equally or more exposed to the initial shock, simply because they drew on their capacities and responded in a different (e.g., more appropriate) way than other households to the shock. This combined nature of the effect of the shock, capacities and the response(s) that individuals, households or communities adopt is represented graphically in Figure 4.

We consider this response as partially "transformative" because it is in line with the initial definition of transformation as presented in Walker et al. (2004: 5): 'to create a fundamentally new system when ecological, economic, or social structures make the existing system untenable'. 
Figure 4. Conceptual representation of a resilience framework

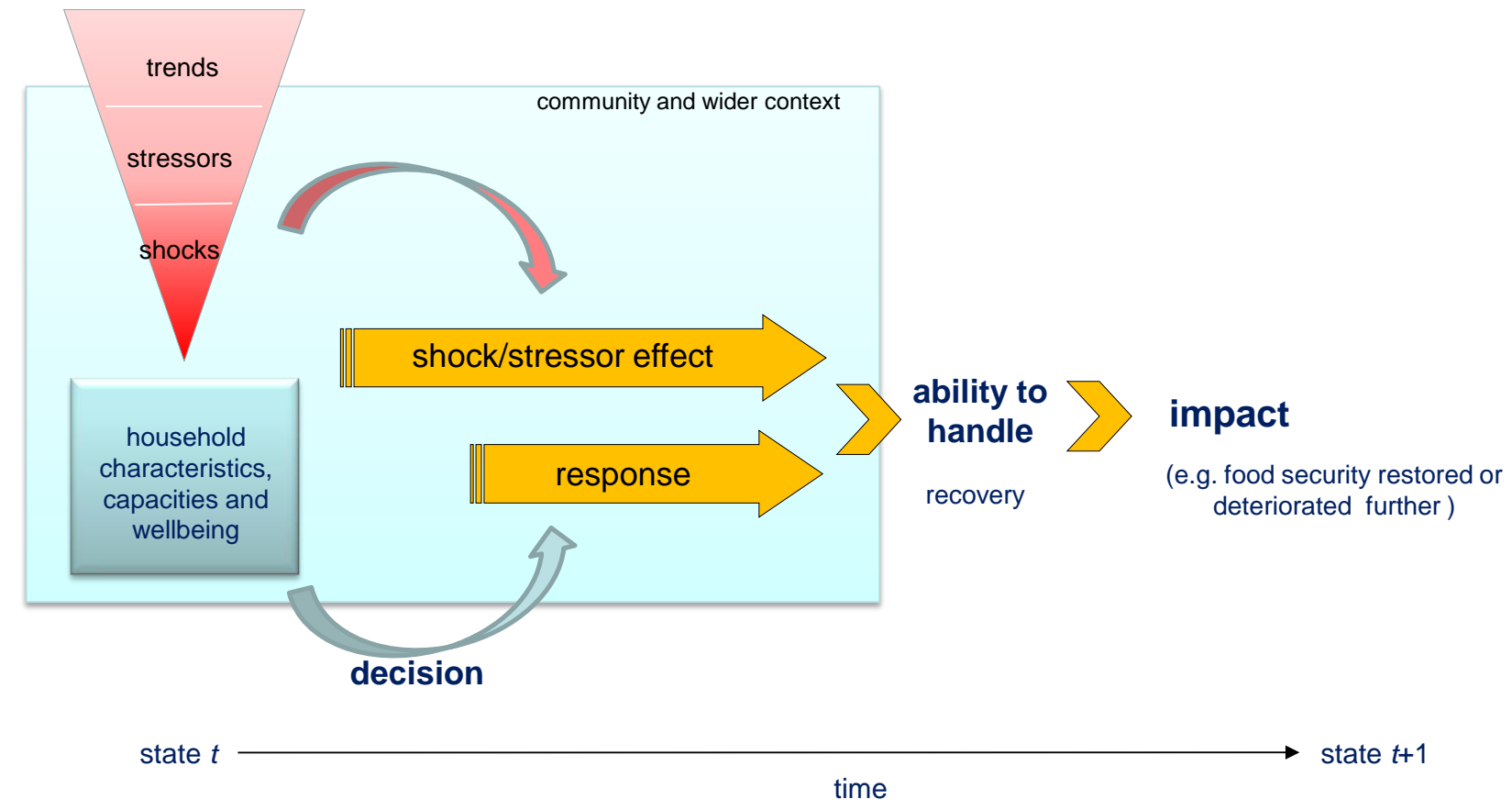

Source: authors' own.

Note, however, that this framework, which is conceptually useful to highlight the distinction between the direct effect of an event and a response, is nevertheless slightly reductionist in the sense that it assumes that events and responses occur within distinguishable cycles (one event $\rightarrow$ one response $\rightarrow$ recovery $\rightarrow$ measurable impact). The reality faced by households living in risk-prone areas or in zones of recurrent crises such as droughts is one where the continuous effect of recurrent and/or permanent shocks often results in failure to recover before the next shock strikes, which can ultimately lead to a downward spiral of divestment, destitution, and increase reliance on humanitarian assistance - either seasonally or permanently.

\subsection{More than just vulnerability analysis}

Another important progress that was made in recent years is that resilience analysis should include - and go beyond - a vulnerability analysis. Typically, a vulnerability assessment focuses on the (participative) identification of the shocks, risks and stressors that affect people's livelihoods at multiple levels. As such vulnerability is useful for understanding how people are exposed to a hazard or longer-term disturbance, how this differs between different groups, and ideally what the root causes of this vulnerability are. Resilience analysis adds to vulnerability analysis in at least two domains. First, resilience analysis considers two elements that are not usually included in vulnerability analysis: (i) the identification of existing absorptive, adaptive and transformative capacities and (ii) the analysis of the responses that individuals, households and communities put in place following (or in anticipation of) the shocks and stressors identified through the vulnerability assessment. Second, resilience analysis shifts emphasis from a perception of passive, vulnerable "victims" of an event/disaster, to an "active" agent reacting to that event. Indeed, acknowledging that resilience is about the capability of individual, households or community members to adapt, change, anticipate, or respond-in this case to shocks and (future) uncertainty-is also recognising that resilience is about agency and about the ability of people to make informed decisions that have an effect on their own lives (Béné et al. 2014). 


\subsection{Resilience capacity is measured at multiple levels and scales}

Much has already been said about the necessity to recognise the multi-scalar and multi-level nature of resilience (see Constas et al. 2014a: 11; Béné 2013, Fig.3). In particular, the literature stresses the central importance of the intimate links between resilience at household and community levels and the condition of the agro-ecological system (i.e., higher level systems) on which they depend. Although these links are yet to be rigorously demonstrated, there is a wide consensus amongst academics and practitioners that such links exist and are critical.

What we argue here is that acknowledgement of the need for a multi-scalar, multi-level approach to measuring capacity also applies to measuring the responses put in place by individuals, communities or even societies. Current resilience measurement practices focus on the "recipients" (i.e., targeted households and communities) of the intervention(s). However, the ultimate effect of a shock or stressor - on the targeted population - does not depend only on their responses. Rather, the effect of a shock or stressor on a target population also depends on how other - non-direct beneficiary - actors respond to the shock or stressor and at what level (e.g., local, district, provincial). For example, local authorities may implement responses that reduce the ultimate effect of a shock or stressors for certain groups within a community, but may increase it for others. The 2011 flood in Bangkok serves as an example. As the flood threat continued to increase in October 2011, efforts to build additional sandbag flood walls were undertaken by the municipal authorities in order to prevent the Chao Phraya River from overflowing into the city. While the flood walls were successful at keeping the centre part of Bangkok dry, they essentially diverted the flood of the Chao Phraya River to several districts in eastern Bangkok that were located outside the flood wall and were thus severely affected by flooding that resulted from the diversion. ${ }^{5}$

Resilience analysis should include therefore an evaluation of the effect of different resilience responses at multiple levels (i.e., households, communities, local, provincial and national authorities). This is particularly important in terms of power dynamics and political willingness (or lack thereof) to ensure equitable responses to shocks and stressors. Thus, the trade-offs between different resilience-building approaches need to be assessed in terms of their effects not only on target populations but on other components of the system (Leach 2008).

\subsection{Building resilience capacities}

If resilience is about the ability of individuals, households, communities, or local/national authorities to adequately deal with shocks and stressors, then resilience interventions should be designed around capacity building activities that reduce engagement of those individuals, households, communities and local/national authorities in detrimental responses while at the same time increase their ability to adopt appropriate responses to shocks and stressors through improved absorptive, adaptive or transformative capacity.

The relationship between shock exposure, resilience capacity, and wellbeing outcomes was recently examined in a study of the Pastoralist Areas Resilience Improvement and Market Expansion (PRIME) project in Ethiopia (Smith et al. 2014). Results suggest not only that increased resilience capacity has a positive impact on household food security (even after controlling for wealth), but that transformative capacity has a greater impact than adaptive capacity, which has a greater impact than absorptive capacity. Households with greater resilience capacity are likely to have greater food consumption, higher dietary diversity, reduced food insecurity overall (as measured using the Household Food Insecurity Access Score (HFIAS)), and reduced hunger. These results suggest that households with higher resilience capacity are better able to withstand and recover from shocks through not only improved absorptive, adaptive or transformative capacity, but also through improved 
responses. Although shock exposure increases household food insecurity, resilience capacity helps to reduce the negative impacts of shocks.

The resilience capacity-mediated relationship between shock exposure and household food insecurity is illustrated in Figure 5 (Smith et al. 2014). It shows the implied impact of shock exposure on the HFIAS at three values of the resilience capacity index: the mean, the mean minus ten points, and the mean plus ten points. The smaller is the slope of the line, the higher is the level of resilience capacity. Further, as resilience capacity increases, food insecurity decreases for any given level of shock exposure.

Figure 5. Resilience capacity-mediated relationship between shock exposure and household food insecurity (HFIAS)

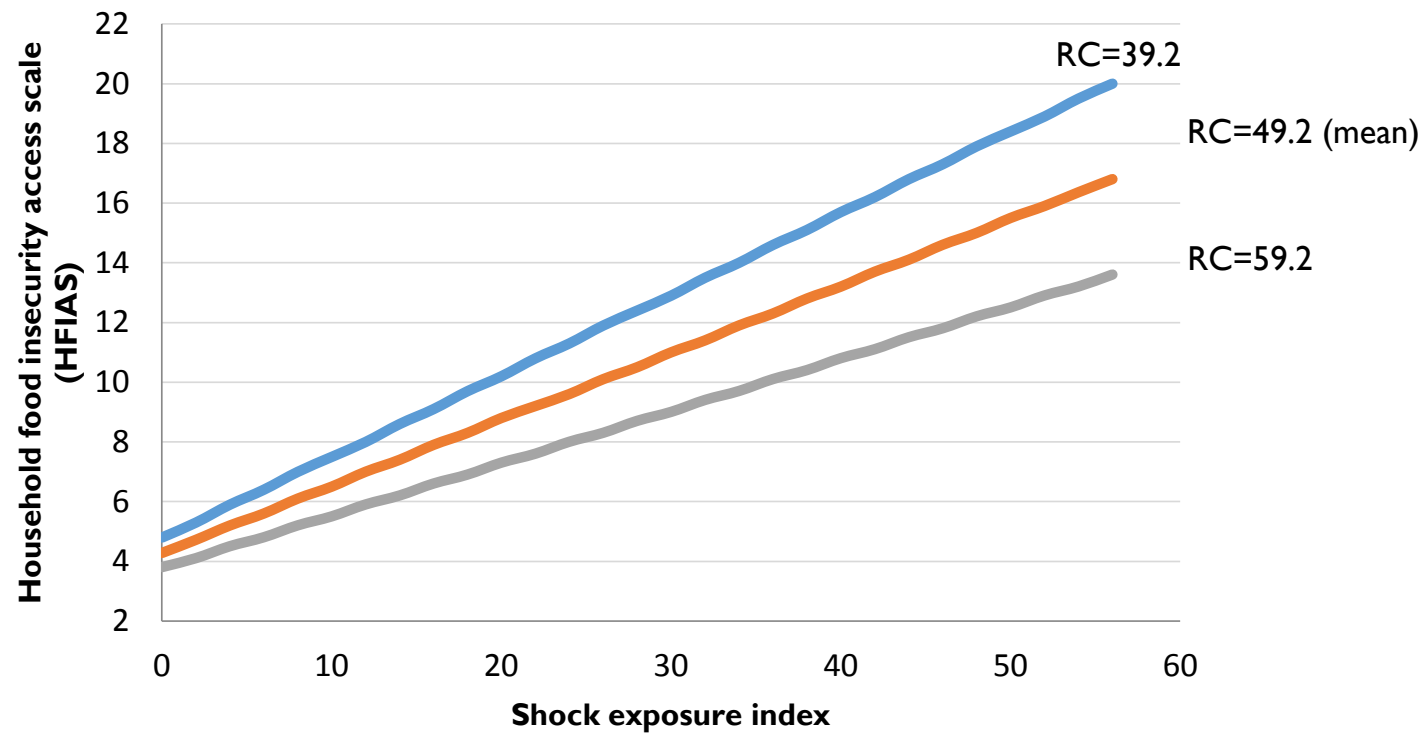

NOTE: The figure shows the relationship between the shock exposure and the HFIAS implied by regression results at three different values of the resilience capacity index, the mean (49.2) $+/-10$ points. RC==Resilience Capacity.

\section{Monitoring and evaluation of resilience interventions}

To structure the discussion and in particular identify the appropriate indicators to be measured as part of the M\&E system of a resilience intervention, we propose to start with a logical framework approach (i.e., logframe) as currently adopted in the majority of development programmes. A conventional logframe would include the following components: input $=>$ activities $=>$ outputs $=>$ intermediate outcome $=>$ outcome $=>$ impact. Figure 6 summarises these components for a resilience programme, including the nature of indicators, levels of interventions, and frequency of data collection. Illustrative examples of indicators are also presented. 
Figure 6. Logframe for M\&E of resilience programming interventions ${ }^{6}$

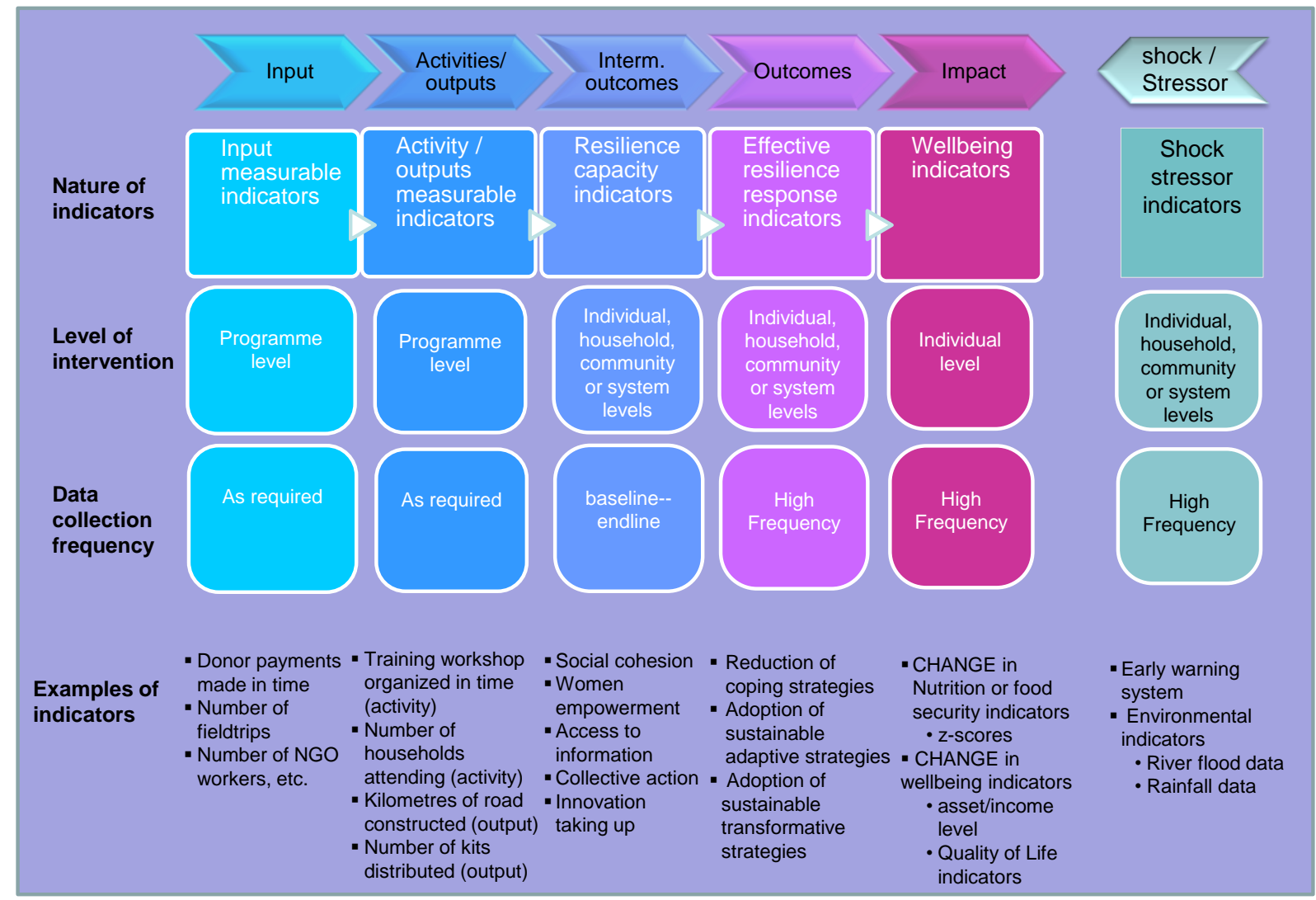

Source: authors' own.

Some of the indicators to be used in an M\&E plan for a resilience-building programme do not necessarily differ from the types of monitoring data that are currently measured in any programme being properly monitored. These include:

- Indicators of programme inputs such as the number of field staff involved in programme implementation or percentage of the total budget allocated to different activities.

- Indicators of programme activities/outputs such as number of training workshops delivered, percentage of women attending from targeted households or communities, kilometres of roads built, dykes constructed, people trained.

These indicators should be collected at the programme level and the frequency of monitoring should be based on the deliverable schedule.

\subsection{Intermediate outcome indicators}

As indicated above, resilience can be conceptualised as the combination of three types of capacities: absorptive, adaptive, and transformative capacities. These capacities are interconnected, mutually reinforcing, exist at multiple levels (e.g., individual, household, community, district, national, ecosystem) and are built or strengthened through project 
interventions. In this sense, they represent intermediate outcomes in that they are necessary results along the pathway to achieving the project's overall goal or impact (i.e., improved wellbeing).

Absorptive capacities - Improving the absorptive capacity of households and communities facilitates their ability to cope with the impacts of shocks and stressors without incurring permanent, negative effects on their longer-term livelihood security. Interventions should consist of preventative measures and coping strategies that allow for quick recovery while avoiding permanent, negative impacts. Interventions often also include Disaster Risk Reduction/Disaster Risk Management (DRR/DRM) approaches, risk-financing mechanisms (e.g., crisis-modifiers) to trigger early response, improved access to savings, and informal safety nets (i.e., bonding social capital). Additionally, cash or in-kind transfers contribute to absorptive capacity by helping protect household assets and food security in the face of shocks and stressors.

Adaptive capacities - Adaptive capacities of households and communities are strengthened by improving their ability to make pro-active and informed decisions about alternative livelihood strategies based on an understanding of changing conditions (Levine, Ludi and Jones 2011). Interventions may include both humanitarian and development activities, and typically focus on livelihoods diversification, climate change adaptation (CCA), human capital (e.g., skills building, health and nutrition status, education), asset accumulation and diversification, climate-smart agriculture, and access to financial services (e.g., credit).

Transformative capacities - Long-term and sustainable resilience building is not possible without building transformative capacity, which addresses the underlying drivers of risk and vulnerability, and promotes social cohesion through public assets and human capital (TANGO 2015). Transformative capacity refers to system-level changes that enable more lasting resilience and often challenge the status quo in a substantial way (O'Brien 2012). It is enhanced through investments in good governance, infrastructure (e.g., markets, roads, communications systems), formal and informal social protection mechanisms, basic service delivery (e.g., health, education, sanitation, water), and policies/regulations that constitute the enabling environment necessary for systemic change (i.e., enable households to maintain good health and nutrition, diversify or even change their livelihoods, and to exercise their individual and collective rights). ${ }^{7}$

Empirical evidence on what factors contribute to resilience capacities and under what contexts is limited - though growing. At the present time, many implementing partners, practitioners, and academics rely on "logical" (or gut-feeling) assumptions - some of which may still need to be more systematically tested and/or verified. For example, it may be reasonable to assume that social capital or social cohesion would have a positive effect on resilience capacity (Boyd et al. 2008; Schwarz et al. 2011), and social capital was shown for instance to have a strong impact on resilience capacity in the PRIME Impact Evaluation study (Smith et al. 2014). Yet other empirical studies suggest that this is not the case in all circumstances. Rather, there may be cases where forms of social capital (e.g., social cohesion) can in some specific circumstances be non-adaptive and jeopardise long-term wellbeing. Coulthard (2011) shows how fishing communities in India that are characterised by a very strong social identity associated with their traditional customary management system (called the Padu system) turned out to be less resilient than groups that have less loyalty to these customary systems; 'the high social values attributed to the Padu system, alongside complex power structures, [had] hinder[ed] institutional adaptation' and prevented the community from engaging in the transformation of their livelihood basis that was necessary to "survive" the drastic changes they were facing (Coulthard 2011: 405). Thus, 
although certain assumptions (e.g., social capital contributes positively to resilience) seem reasonable, supposing a strict linear relationship is over-simplistic and more nuanced analyses is still required.

Notwithstanding the potential for a negative relationship between resilience and certain "assumed" resilience-enhancing factors, intermediate programme outcomes should be measured through changes in resilience capacities, i.e., the factors that make up absorptive, adaptive, and transformative capacities. For instance, if women's empowerment is recognised to contribute to strengthened resilience capacity in the target group, specific intermediate outcome indicators that capture changes in the level of women's empowerment should be included in the M\&E plan. All these changes are linked to the programme's activities (e.g., training) and these different resilience capacity indicators should be monitored as part of the follow-up of the programme baseline (prior to the start of programme activities) and in the endline survey. ${ }^{8}$

\subsection{Outcome indicators}

The next important group of indicators to be considered are the outcome indicators (i.e., results). These correspond to effective resilience response indicators which need to be monitored through high frequency data collection activities. There is currently much on-going discussion in the literature regarding what these indicators are or should be (e.g., Barrett and Heady 2014). Following the logframe approach presented above, a resilience outcome indicator should confirm that the targeted group (individuals, households, communities) is able to effectively respond to and recover from a shock or stressor in an appropriate manner. These outcomes are effectively the responses implemented by stakeholders as an attempt to deal with a shock or stressor (cf. Fig.4 above). In essence, these represent the results of programme interventions designed to improve resilience capacity response of the targeted group.

In the context of food security as the measure of overall programme impact, the Coping Strategies Index (CSI) (CARE and WFP 2003; Maxwell and Caldwell 2008) represents a viable outcome indicator as it measures the occurrence of specific detrimental coping strategies (Table 1). Thus, resilience-building interventions should include activities that aim at reducing the occurrence of these detrimental coping strategies in the aftermath of a shock (i.e., households' CSI should go down if the project has been successful).

Note however that the CSI focuses on short-term consumption-related behaviour after a shock or stressor. Other short-term ex-post responses might also be relevant such as these focusing on cash or money-borrowing strategies, easily measured by indicators that capture access to or utilisation of financial services (e.g., savings groups, credit). The long-term impact of accessing credit could potentially have a detrimental effect, depending on where (or from whom) the money is borrowed.

Measuring resilience capacities provides a measure of progress that can be particularly useful (at least once their mediating effect between shocks on one hand and wellbeing outcomes on another have been empirically established) in the event shocks do not occur during the span of the programme. 
Table 1. Coping Strategy Index (CSI)

1 Dietary change

a. Rely on less preferred and less expensive foods

2. Increase short-term household food availability

b. Borrow food from a friend or relative

c. Purchase food on credit

d. Gather wild food, hunt or harvest immature crops

e. Consume seed stock held for next season

3. Decrease number of people

f. Send children to eat with neighbours

g. Send household members to beg

4. Rationing strategies

h. Limit portion size at mealtimes

i. Restrict consumption by adults in order for small children to eat

j. Feed working members of household at the expenses of non-working members

k. Reduce number of meal eaten in a day

I. Skip entire days without eating

Source: Maxwell and Caldwell (2008).

Improved resilience capacity, however, is not simply about avoiding detrimental short-term response strategies that undermine absorptive capacity in particular. It is also about nurturing or fostering the ability of actors to engage in positive and sustainable responses that improve all three resilience capacities, i.e., absorptive, adaptive, and transformative capacity. A good example of effective resilience behaviour would be the increased use of early warning system information amongst nomadic communities in arid or semi-arid regions for making decisions on livestock movement or destocking, or, in the context of the typhoon-prone coastal areas of many South East Asia countries, the increase in percentage of population that are aware of, have access to, and effectively use typhoon shelters.

\subsection{Impact indicators}

If we accept that the ultimate goal of resilience programming is not achievement of resilience per se, but rather improvement (or at a minimum non-deterioration) of long-term individual or household wellbeing in the face of shocks and stressors, then the indicators used to measure programme impact should be capturing the change in an individual's or household's wellbeing. Appropriate indicators could include nutritional indicators (e.g., child weight-forage z-score), food security indicators (e.g., HFIAS) (Coates, Swindale and Bilinsky 2007), monthly expenditure per capita, subjective wellbeing indicators (OECD 2013), or psychological indicators such as post-traumatic stress disorder (PTSD) or the CES Depression Scale (CES-D) (Kohn et al. 2005).

However, the critical point to understand is that the absolute value of these indicators is not informative with regards to individual or household levels of resilience. The absolute value of a z-score tells us about the actual severity of malnutrition, but does not tell us about the degree to which that level of malnutrition results from a particular shock or stressor; nor does it tell us about the connection between exposure to a given shock or set of shocks that might 
be mediated by a given resilience capacity or combination of capacities. It is only the change observed in the value of the indicator following the event (compared to its value prior to the event) that indicates the relative impact of that event on the indicator. ${ }^{9}$

One direct implication of this is that resilience measurement will only be possible if the wellbeing indicators are measured with a high enough frequency to capture these changes. For instance, the Ethiopia's PRIME Impact Evaluation is utilising a real-time recurrent monitoring system to capture exposure (incidence and severity) to shocks and stressors as well as real-time responses by households (TANGO 2015). Triggered by a shock or stressor, monitoring involved interim panel surveys (i.e., using a subset of households surveyed at baseline) conducted every two months over a 12-month period. The brief (20-minute) interim survey included modules on shocks and recovery, productive assets, access to and use of services, Household Hunger Scale (HHS) and Household Dietary Diversity Score (HDDS), coping strategies, and confidence and risk tolerance.

\subsection{Shocks and stressors indicators}

The last specific component that also needs to be monitored regularly in a resilience programme is the shocks/stressors component. Although an increasing number of living standard household surveys propose some form of module for measuring shocks, a lack of standardisation and uniformity (e.g., in definitions and terms) across surveys would need to be addressed in order for accurate and comprehensive resilience measurement to occur (Carletto, Zezza and Banerjee 2015). Perhaps even more limiting is the low frequency at which these surveys are typically conducted, making it difficult to capture how resilience responses - particularly to different types of shocks - may change over time.

To monitor shocks and stressors, indicators expected to reflect sudden changes - or slower trends - in the risk landscape (e.g., river water level, rainfall) should be regularly recorded at the relevant spatial scale and at frequencies that are appropriate to capture their dynamics (e.g., variability, seasonality). Ideally three levels of indicators could be considered: at the national (or higher) level through national early warning systems (e.g., IPC, FEWSNET); at a local level through community-based early warning systems; and at the household level to capture household perceptions of shocks and their ability to recover.

There are two distinct but related reasons for measuring shocks and stressors as part of M\&E for resilience programmes. First, it would be impossible to assess the success (or lack thereof) of a particular resilience programme unless one can measure simultaneously the occurrence of the shocks or stressors, the resilience responses adopted by the programme's beneficiaries as an attempt to handle the shocks and stressors (i.e., the outcome), and the ultimate impacts of the combined effect of the shock and the response as measured by changes in wellbeing indicators of the targeted population. Second, measurement of the shocks and stressors, along with the programme's intermediate outcomes, outcomes and impact also enhances our own understanding about "resilience dynamics" by systematically looking for emerging patterns and potential correlations between intermediate outcomes (i.e., capacities), outcomes (i.e., responses), and impacts (i.e., wellbeing indicators). Figure 5 is an example of these types of potential correlations.

\subsection{Data collection}

The type of data, as well as the timing and frequency of its collection are key aspects of M\&E for resilience programming. In order to capture the dynamics of shocks (which are often unpredictable), the types of responses employed, and the impact on individual or household

This is where the link to the more engineering interpretation of the concept of resilience can be useful. This literature identifies broadly two key dimensions in the 'measurement' of resilience: the 'depth' or severity of the change (i.e., the relative change in the indicator following the shock) and the time of recovery (i.e., the time it takes for the indicator to return to its original values after the shock) (Ludwig, Walker and Holling 1997). 
wellbeing, high frequency monitoring (e.g., monthly, bi-monthly, quarterly) is required. In order to follow changes in response that occur at the household level, panel data should be collected (i.e., from the same households) as the baseline. A sub-optimal option is to use quasi-panel data, i.e., data collected from the same communities (as opposed to the same households). In that case, however, the level of analysis would have to be the community, not the household. Helen Keller International's nutrition surveillance programme (NSP) provides an example of using high frequency (bi-monthly) quasi-panel data sets (Bloem, Moench-Pfanner and Panagides 2003).

In addition to the frequency and the panel-nature of the data, the length of time over which data should be collected needs to be considered. The responses used to deal with a shock may vary over time, potentially becoming more negative with a lack of recovery. A timesensitive component was included in the resilience model described by the Resilience Measurement Working Group in order to capture how changes in the factors contributing to resilience capacity change over time (Constas et al. 2014b). For example, long-term wellbeing may be sacrificed in order to meet "more urgent" wellbeing needs. Thus, data collected over a short period of time after a shock may not adequately capture response dynamics. At a minimum, 6-9 months post-shock should be considered, although longer might be even more informative.

\subsection{Monitoring contextual changes}

Finally, M\&E systems for resilience programmes need to monitor changes in context in order to determine if adjustments are needed to the programme's theory of change for promoting resilience. Contextual factors that need to be taken into account include a wide range of political, agro-ecological, economic and cultural conditions that not only affect underlying vulnerabilities but also influence how households, communities, and higher-level systems respond to shocks and stressors.

\section{Conclusion}

As resilience programming gains more and more prominence as an approach for addressing chronic vulnerability of populations exposed to recurrent shocks and stressors, empirical evidence will be needed for measuring how well households, communities, and higher-level systems manage shocks and stressors and how interventions and programmes that are designed to strengthen their resilience capacities, perform. M\&E systems measuring outcomes and impacts of these interventions will become key in providing such information. As argued in this paper, in order to do so, these M\&E systems will need to focus on how to measure the occurrence of the shocks or stressors, resilience capacities (intermediate outcome), and the resilience responses adopted by the programme's beneficiaries as an attempt to handle the shocks and stressors (i.e., outcomes). These M\&E systems will also need to measure the ultimate impacts of the combined effect of shocks and responses through changes in wellbeing indicators of the targeted population (i.e., impacts).

This paper explores the different steps necessary to monitor and evaluate a resilience programme, the overall structure of which does not completely differ from that of other M\&E systems (i.e., for "conventional" programmes). ${ }^{10}$ In fact some of the steps and indicators are quite similar (in particular monitoring of, and indicators for inputs, activities, and outputs). The intermediate outcomes and outcomes components described in Figure 6, however, will differ more significantly from a conventional M\&E system in the sense that in a resilience programme intermediate outcomes correspond to indicators of absorptive, adaptive or

10 With the exception, however, of the shock/stressor monitoring component, which is quite specific to resilience monitoring. 
transformative capacities. They are defined as intermediate outcomes in a resilience M\&E system because they measure whether individuals, households, communities or higher-level systems have gained or strengthened one or more of these resilience capacities and whether they are on a resilience pathway. In a "conventional" development programme (especially those focusing on capacity building), changes in these capacities would more typically be considered as (higher-level programme) outcomes, or even as impacts. M\&E systems designed for resilience programmes, however, should measure outcomes through indicators of resilience response (i.e., how people responded). In that regard, appropriate resilience response indicators include those that measure changes in both positive and negative behaviours. For example, a reduction in the adoption of detrimental coping strategies (i.e., a lower CSI) might serve as one universal indicator in resilience programmes. However, resilience response indicators should also measure changes in adaptive and transformative behaviour, such as increases in the adoption of appropriate responses by households or communities as well as decreases in the prevalence of maladaptive responses. Those indicators monitoring the occurrence of appropriate/inappropriate responses are expected to have a strong local (spatial and temporal) connection that reflects the specific nature of the initial event(s) to which the households/communities are responding. These responses also have to be understood in relation to the specific social and ecological contexts and constraints within which these households are operating.

Finally, the M\&E system of a resilience programme also differs in the way the impact is monitored. Regardless of what wellbeing measures are used as indicators of impact (e.g., zscore, household assets, HFIAS or PTSD), what is important to monitor is the change in the value of that indicator. Only the change observed in the value of the impact indicator following the event (compared to its value prior to the event) will inform us about the actual success/effectiveness of the resilience intervention. The importance of this point cannot be overemphasised. Too often measures of resilience proposed in the literature are wrongly associated with the measurement of absolute values of wellbeing (or food security) indicators. By definition, what matters from a resilience viewpoint is the relative change (or absence of change) in these indicators in the face of shocks.

Last but not least, the M\&E system of a resilience programme will finally differ from a conventional M\&E by one more aspect: the frequency of measurement. In order to capture the dynamics of the change in the impact indicators, but also to monitor shocks, as well as the responses employed (the outcome of the programme), high frequency monitoring will be required. 


\section{Annex 1. Resilience conceptual framework}

\section{Resilience Framework}

$\begin{array}{cc}\text { Context } & \text { Disturbance } \\ \text { e.g., social, } & \text { e.g., natural } \\ \text { ecosystems, } & \text { hazard, conflict, } \\ \text { political, } & \text { food shortage, } \\ \text { religious, etc. } & \text { fuel price }\end{array}$

$\begin{array}{ccc}\text { Absorptive, adaptive } & \text { Adaptive } & \text { Reaction to disturbance } \\ \text { and transformative } & \text { state to } & \text { e.g., survive, cope, recover, }\end{array}$ capacities
Livelihood Outcomes

$$
\text { increase }
$$

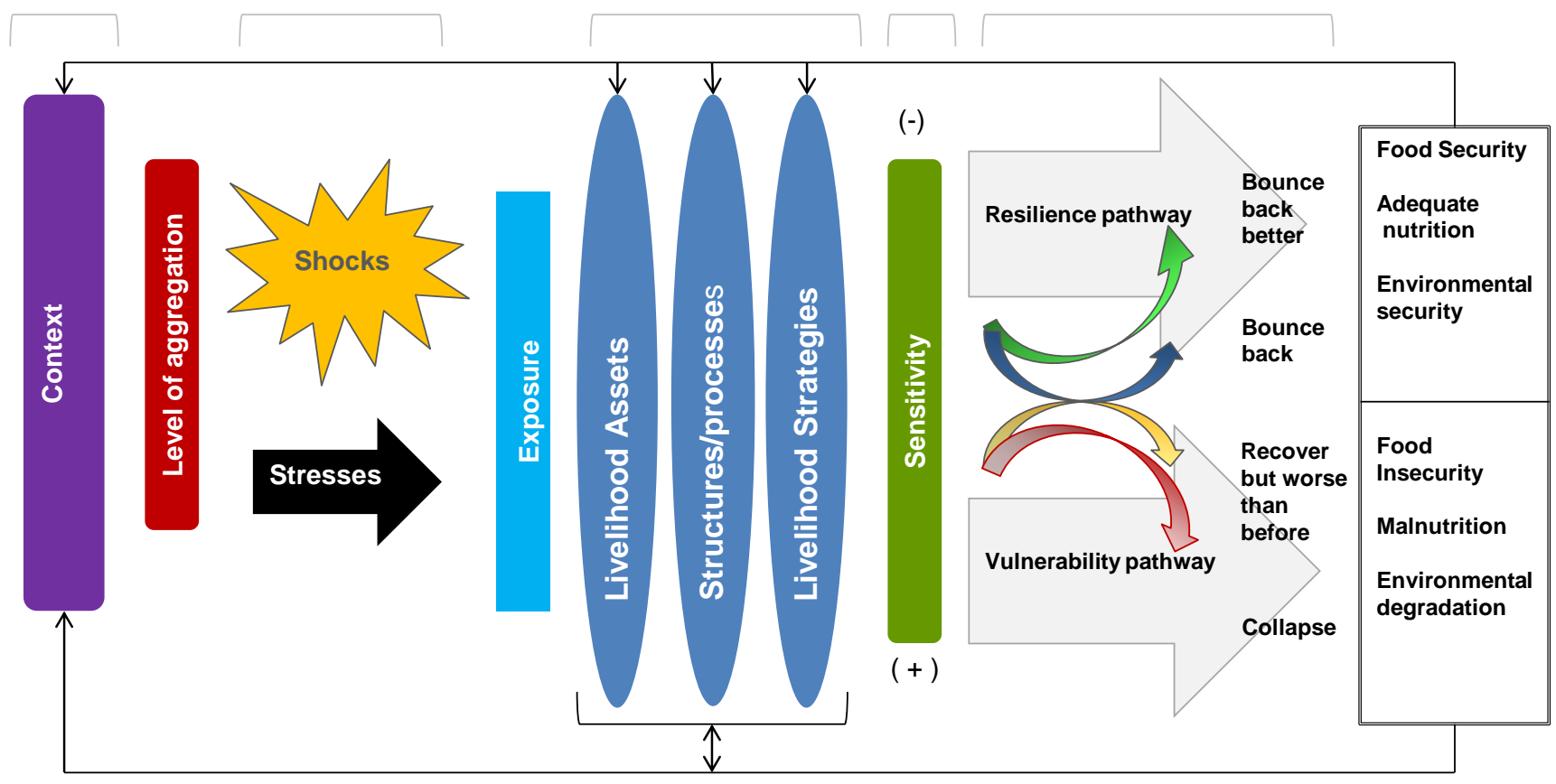




\section{Glossary}

Adaptive capacity - The ability to make proactive and informed choices about alternative livelihood strategies based on changing environmental, climatic, social, political and economic conditions.

Absorptive capacity - The ability of individuals, households, communities or higher-level systems to minimise their exposure to shocks and stresses and to recover quickly when exposed.

Conflict - Organised violence that includes the use or threat of physical force by a group or groups. These include state actions against other states or against civilians, civil wars, electoral violence between opposing sides, communal conflicts based on regional, ethnic, religious, or other group identities or competing economic interests, gang-based violence and organised crime and international non-state armed movements with ideological aims (World Bank 2011).

Disaster - Severe alterations in the normal functioning of a community or a society due to hazardous physical events interacting with vulnerable social conditions, leading to widespread adverse human, material, economic or environmental effects that require immediate emergency response to satisfy critical human needs and that may require external support for recovery (IPCC 2014).

Exposure - The magnitude, frequency, and duration of shocks or stressors.

Hazard - The potential occurrence of a natural or human-induced physical event or trend that may cause loss of life, injury, or other health impacts, as well as damage and loss to property, infrastructure, livelihoods, service provision, ecosystems and environmental resources (IPCC 2014).

Resilience - The capacity that ensures stressors and shocks do not have long-lasting adverse development consequences.

Risk - The potential for adverse consequences of an uncertain event or trend on lives, livelihoods, health, property, ecosystems and species, economic, social and cultural assets, service provision (including environmental services) and infrastructure (IPCC 2014).

Shocks - External short-term deviations from long-term trends that have substantial negative effects on people's current state of wellbeing, level of assets, livelihoods, or safety, or their ability to withstand future shocks (Zseleczky and Yosef 2014).

Stressors - Long-term trends or pressures that undermine the stability of a system and increases vulnerability within it (Bujones et al. 2013).

Transformative capacity - The ability to create an enabling environment through investment in good governance, infrastructure, formal and informal social protection mechanisms, basic service delivery, and policies/regulations that constitute the conditions necessary for systemic change.

Vulnerability - The degree to which a system is susceptible to, or unable to cope with, the adverse effects of or harm due to exposure to a hazard. 


\section{References}

Barnett, J. and O'Neil, S. (2013) 'Maladaptation', Global Environmental Change 20: 211-13

Barrett, C. and Headey, D. (2014) 'Measuring Resilience in a Volatile World: A Proposal for a Multicountry System of Sentinel Sites', 2020 Conference Paper 1, Washington DC: International Food Policy Research Institute

Béné, C. (2013) Towards a Quantifiable Measure of Resilience, IDS Working Paper 434, Brighton: IDS

Béné, C.; Godfrey-Wood, R.; Newsham, A. and Davies, M. (2012) Resilience: New Utopia or New Tyranny? - Reflection about the Potentials and Limits of the Concept of Resilience in Relation to Vulnerability Reduction Programmes, IDS Working Paper 405, Brighton: IDS

Béné C.; Newsham, A.; Davies, M.; Ulrichs, M. and Godfrey-Wood, R. (2014) 'Resilience, Poverty and Development', Journal of International Development 26: 598-623

Berkes, F.; Colding, J. and Folke, C (2003) Navigating Social-Ecological Systems: Building Resilience for Complexity and Change, Cambridge: Cambridge University Press

Black, R.; Bennett, S.R.G.; Thomas, S.M. and Beddington, J.R. (2011) 'Comment: Migration as Adaptation', Nature 478: 447-9

Bloem, M.W.; Moench-Pfanner, R. and Panagides, D. (2003) Health and Nutritional Surveillance for Development, Singapore: Helen Keller Worldwide

Boyd, E.; Osbahr, H.; Ericksen, P.; Tompkins, E.; Carmen Lemos, M. and Miller, F. (2008) 'Resilience and "Climatizing" Development: Examples and Policy Implications', Development 51: 390-6

Brown, K. (2013) Resilience, Development and Global Change, Routledge: 316 p

Bujones A.; Jaskiewicz, K.; Linakis, L. and McGirr, M. (2013) A Framework for Analyzing Resilience In Fragile and Conflict-Affected Situations, USAID Final Report, Columbia University SIPA 2013

CARE and WFP (2003) The Coping Strategies Index: Field Methods Manual, Nairobi: CARE and WFP. www.wfp.org/content/coping-strategies-index-field-methods-manual-2ndedition

Carletto, C.; Zezza, A. and Banerjee, R. (2015) 'Data Sources for Measuring and Understanding Resilience', DRAFT, for discussion at the Resilience Measurement Technical Briefing, Food Security Information Network

Coates, J.; Swindale, A. and Bilinsky, P. (2007) Household Food Insecurity Access Scale (HFIAS) for Measurement of Household Food Access: Indicator Guide, Washington DC: Food and Nutrition Technical Assistance Project, Academy for Educational Development

Constas, M.; Frankenberger, T. and Hoddinott, J. (2014a) Resilience Measurement Principles: Toward an Agenda for Measurement Design, Food Security Information Network (FSIN) Technical Series No. 1, Rome: World Food Programme 
Constas, M., Frankenberger, T.; Hoddinott, J.; Mock, N.; Romano, D.; Béné, C. and Maxwell, D. (2014b) A Common Analytical Model for Resilience Measurement: Causal Framework and Methodological Options, Food Security Information Network (FSIN) Technical Series No. 2, Rome: World Food Programme

Coulthard, S. (2011) 'More than just Access to Fish: The Pros and Cons of Fisher Participation in a Customary Marine Tenure (Padu) System Under Pressure', Marine Policy 35: 405-12

Dercon, S.; Hoddinott, J. and Woldehanna,T. (2005) 'Shocks and Consumption in 15 Ethiopian Villages, 1999 - 2004', Journal of African Economies 14.4: 559-85

Devereux, S. and Sabates-Wheeler, R. (2004) Transformative Social Protection, IDS Working Paper 232, Brighton: IDS

DFID (2012) Guidance on Using the Revised Logical Framework. Value for Money Department, Department for International Development. www.gov.uk/government/uploads/system/uploads/attachment data/file/253889/usingrevised-logical-framework-external.pdf

DFID (1999) Sustainable Livelihoods Guidance Sheets, Numbers 1-8, London: Department for International Development

Frankenberger, T. (1995) Household Livelihood Security: A Unifying Conceptual Framework for CARE Programming, Atlanta: CARE

Frankenberger, T.; Constas, M.; Nelson, S. and Starr, L. (2014) Resilience Programming among Nongovernmental Organizations: Lessons for Policymakers, Food Policy Report, 2020 Vision, Washington DC: IFPRI

Hoddinott, J. (2006) 'Shocks and their Consequences Across and Within Households in Rural Zimbabwe', The Journal of Development Studies 42.2: 301-21

IFPRI (2014) 'Building Resilience for Food and Nutrition Security. Highlights from the 2020 Conference', Addis Ababa, 15-17 May 2014, Washington DC: IFPRI

IPCC (2014) 'Annex II: Glossary' [Mach, K.J., S. Planton and C. von Stechow (eds.)], in The Core Writing Team, R. K. Pachauri and L. A. Meyer (eds), Climate Change 2014: Synthesis Report. Contribution of Working Groups I, II and III to the Fifth Assessment Report of the Intergovernmental Panel on Climate Change, Geneva, Switzerland: IPCC

Kazianga, H. and Udry, C. (2006) 'Consumption Smoothing? Livestock, Insurance and Drought in Rural Burkina Faso', Journal of Development Economics 79.2: 413-46

Kohn, R.; Levav, I.; Donaire, I.; Machuca, M. and Tamashiro, R. (2005) Psychological and Psychopathological Reactions in Honduras following Hurricane Mitch: Implications for Service Planning, Review of Panamerican Salud Publications

Leach, M. (2008) Re-framing Resilience: A Symposium Report, STEPS Working Paper 13, Brighton: IDS

Levine, S.; Ludi, E. and Jones, L. (2011) Rethinking Support for Adaptive Capacity to Climate Change - The Role of Development Interventions, a report for the Africa Climate Change Resilience Alliance, London: Overseas Development Institute

Ludwig, D.; Walker, B. and Holling, C.S. (1997) 'Sustainability, Stability, and Resilience', Conservation Ecology 1.1: 7. Available at: www.consecol.org/vol1/iss1/art7/ 
Macintosh, A. (2013) 'Coastal Climate Hazards and Urban Planning: How Planning Responses can Lead to Maladaptation', Mitigation and Adaptation Strategies for Global Change 18.7: 1035-55

Maxwell, D. and Cadwell, R. (2008) The Scoping Strategy Index: Field Methods Manual, Second Edition, Cooperative for Assistance and Relief Everywhere (CARE)

O'Brien, K. (2012) 'Global Environmental Change: From Adaptation to Deliberate Transformation', Progress in Human Geography 36: 667-76

OECD (2013) OECD Guidelines on Measuring Subjective Well-being, Paris: OECD Publishing. Available at: http://dx.doi.org/10.1787/9789264191655-en

Schwarz, A.M.; Béné, C.; Bennett, G.; Boso, D.; Hilly, Z.; Paul, C.; Posala, R.; Sibiti, S. and Andrew, N. (2011) 'Vulnerability and Resilience of Rural Remote Communities to Shocks and Global Changes: Empirical Analysis from the Solomon Islands', Global Environmental Change 21: 1128-40

Scoones, I. (1998) Sustainable Rural Livelihoods: A Framework for Analysis, IDS Working Paper 72, Brighton: IDS

Sinha S.; Lipton, M. and Yaqub, S. (2002) 'Poverty and "Damaging Fluctuations": How do they Relate?' Journal of Asian and African Studies 37.2: 186-243

Smith, L.; Frankenberger, T.; Langworthy, B.; Martin, S.; Spangler, T.; Nelson, S. and Downen, J. (2014) Ethiopia Pastoralist Areas Resilience Improvement and Market Expansion (PRIME) Project Impact Evaluation: Baseline Survey Report, Vol 1. Feed the Future FEEDBACK project report for USAID

TANGO (2015) 'Think Piece: Managing Recurrent Shocks in Food Insecure Countries', paper prepared for the Thematic Team on Reducing Vulnerability and Managing Risk, World Humanitarian Summit

UNDP (2014) Human Development Report 2014 - Sustaining Human Progress: Reducing Vulnerabilities and Building Resilience, New York: United Nations Development Programme

Vaitla, B.; Tesfay, G.; Rounseville, G. and Maxwell, D. (2012) Resilience and Livelihoods Change in Tigray, Ethiopia, Boston: Feinstein International Center, Tufts University

Walker, B.; Holling, C.S.; Carpenter, S.R. and Kinzig, A. (2004) 'Resilience, Adaptability and Transformability in Social-ecological Systems', Ecology and Society 9.2: 5. Available at: www.ecologyandsociety.org/vol9/iss2/art5.

World Bank (2011) Conflict, Security, and Development: World Development Report, Washington DC: The World Bank

Zseleczky, L. and Yosef, S. (2014) 'Are Shocks Really Increasing? A Selective Review of the Global Frequency, Severity, Scope and Impact of Five Types of Shocks', 2020 Conference Paper 5, May 2014, Washington, DC: IFPRI

\section{Websites}

Bangkok Post (2011) Govt Moves to Protect Inner City, 12 October (accessed 9 December 2011). 